\title{
Current State and Future Trends to Optimize the Care of African Americans with End-Stage Renal Disease
}

\author{
Kimberly Harding a Tesfaye B. Mersha ${ }^{b}$ Fern J. Webb ${ }^{c}$ Joseph A. Vassalotti ${ }^{d, e}$ \\ Susanne B. Nicholas ${ }^{f}$ \\ ${ }^{a}$ Monarch Innovation Partners, Rockville, MD, bepartment of Pediatrics, Cincinnati Children's Hospital Medical \\ Center, University of Cincinnati, Cincinnati, $\mathrm{OH},{ }^{c}$ Department of Community Health and Family Medicine, \\ University of Florida College of Medicine, Jacksonville, FL, d National Kidney Foundation, and ${ }^{\mathrm{d}}$ Division of \\ Nephrology, Department of Medicine, Icahn School of Medicine at Mount Sinai, New York, NY, and \\ ${ }^{f}$ Divisions of Nephrology and Endocrinology, Department of Medicine, David Geffen School of Medicine at \\ University of California, Los Angeles, CA, USA
}

\section{Keywords}

End-stage renal disease - African Americans - Health disparities - Care coordination - End of life - Palliative care · Accountable partnerships · Call to action

\begin{abstract}
Background: Chronic kidney disease is a progressive disease, which terminates in end-stage renal diseases (ESRD) that requires either dialysis or kidney transplantation for the patient to survive. There is an alarming trend in the disparities of ESRD in African Americans (AAs). Currently, AAs represent more than $30 \%$ of incident ESRD cases, yet they constitute $15 \%$ of the overall US population. Despite the reductions in mortality, increases in access to patient-centered home dialysis and preemptive kidney transplantation for the overall US ESRD population over the last decade, disparities in the care of AAs with ESRD remain largely unaffected. Summary: This review discusses patient-, community-, and practitioner-related factors that contribute to disparities in ESRD care for AAs. In particular, the review addresses issues related to end-of-life support, the importance of Apolipoprotein-1 gene variants, and the advent of pharmacogenomics
\end{abstract}

\section{KARGER}

(C) 2017 S. Karger AG, Basel toward achieving precision care. The need for accessible clinical intelligence for the ESRD population is discussed. Several interventions and a call to action to address the disparities are presented. Key Messages: Significant disparities in ESRD care exist for AAs. Strategies to enhance patient engagement, education, accountable partnerships, and clinical intelligence may reduce these disparities.

(c) 2017 S. Karger AG, Basel

\section{Introduction}

There is a growing burden with regard to chronic kidney disease (CKD) in the United States, accounting for up to $13.6 \%$ or $\sim 26$ million adults with an associated growing prevalence of individuals with end-stage renal disease (ESRD) [1]. CKD poses a major societal and economic burden. According to the US Renal Data System, more than 661,000 adults have ESRD of which 468,000 individuals receive dialysis therapy [2]. In 2013, the Medicare cost alone for ESRD had increased to USD 31 billion, which represented $>7 \%$ of paid fee-for-service claims [1]. Further, having advanced CKD or ESRD im- 
parts a significant increased risk for morbidity and premature mortality. For example, the 1-year mortality for myocardial infarction is $51 \%$ for populations with CKD stages $3-5$, compared to $36 \%$ for populations without CKD [3]. Kidney disease is the 9th leading cause of death and accounts for more deaths annually than breast or prostate cancer [4]. Importantly, African Americans (AAs) suffer disproportionately from both CKD and ESRD with a prevalent ESRD rate 3.7 times higher than their Caucasian American (CA) counterparts [1]. Although ESRD mortality rates have improved in recent years, the annual rate is still unacceptably high. For example, while the mortality risk for AAs, or Blacks, was equal or higher at all levels of estimated glomerular filtration rates than CAs, the risk was highest for Blacks with estimated glomerular filtration rates $45-95 \mathrm{~mL} / \mathrm{min} / 1.73$ $\mathrm{m}^{2}$ (hazard ratio $1.32,95 \%$ CI 1.27-1.26) [5-8].

The progression toward ESRD is associated with aging, but it is also aggravated and accelerated by other extra-renal factors such as high blood pressure, diabetes, and cardiovascular disease [1]. Furthermore, chemicals, drugs, and environmental pollutants can both initiate kidney disease and promote CKD progression [9]. Additionally, gene-gene and gene-environment interactions in AAs contribute to the increased risk of non-diabetic and hypertension-related ESRD [10-12]. This review discusses the factors that contribute to the disparities in care of AAs with ESRD and provides recommendations to reduce these disparities.

\section{Factors Contributing to Disparities in Care of AAs with ESRD}

\section{AA Patient and AA Community-Related Factors}

Multidimensional factors associated with disparities in ESRD care impact outcomes in AAs. Patient-related factors include psychosocial, demographic, environmental, cultural-behavioral, socioeconomic status (SES), and equal access to ESRD care $[13,14]$. Related factors also span the AA ESRD community understanding of the impact of healthcare policies including medical eligibility to ESRD care. The identification and targeting of several of these factors have the potential to significantly reduce disparities in ESRD care of AAs.

Medicare coverage has successfully reduced many disparities associated with the care of patients with ESRD such as access to dialysis services, delivery of adequate dialysis dose, use of bicarbonate dialysate, and improved management of other dialysis complications

Optimizing Care of AAs with ESRD
[15], but numerous sources of disparities in ESRD unique to the AA community still remain, such as unequal access to higher education, inequitable income level, low awareness of the effects of social determinants of health, low knowledge of their genetic predisposition to ESRD, poor access to education on advanced care planning (ACP), end-of-life (EOL) support and hospice care, as well as unequal access to, and participation in clinical trials.

Equal access to education is an important social determinant that affects AAs with ESRD. In fact, education and income levels have been shown to contribute to excess ESRD rates in AAs [16]. In particular, the Multiple Risk Factor Intervention Trial demonstrated that SES, in terms of lower income, correlated well with excess risk of ESRD in AA men compared to CA men (3.20-1.87, 95\% CI 1.47-2.39) [17]. More recent studies also demonstrated that having low SES significantly influences the incidence of ESRD in AAs compared to CAs [18-20]. Increasing awareness of the effects of social determinants of health may potentially lead to improved clinical outcomes in AAs with ESRD.

The diagnosis of ESRD presents significant challenges to quality of life that are independent of achieving optimum dialysis and care coordination. In general, ESRD patients are confronted with deteriorating health status, struggles with complex dietary restrictions, polypharmacy and complex care coordination for ESRD, and other comorbidities, particularly in the context of common cognitive impairment and frequent depression [21]. For in-center hemodialysis, the chronic dependence on nurses, social workers, nutritionists, technicians, vascular surgeons, and nephrologists for 3-4 h, 3 times a week, or more frequent dialysis sessions for this life-saving procedure limits quality of life, particularly for an aging population. Unlike their CA counterparts, AAs are deeply concerned about disparities in terms of lack of education, awareness of their risks of comorbidities, and fear of healthcare systems [22-24]. Thus, achieving a reasonable quality of life is a challenge. Awareness of ACP and EOL issues represent an important aspect for the AA ESRD patient that may also need added attention.

\section{EOL Decision Support and Palliative Care for AAs with ESRD}

EOL issues including ACP, palliative care and hospice care have been widely explored in the ESRD population. However, in AA and other ethnic minority communities, where low SES is prevalent, discussion about EOL issues

Am J Nephrol 2017;46:156-164 
is typically overshadowed by activities of day-to-day existence and making ends meet [25]. On the other hand, the concerns of estate planning, the transition of one's legacy, and appropriate EOL care may receive higher priority in high SES populations [25]. This disparity may significantly impact one's response to life stressors and perception of mortality. It has been shown that AAs and other ethnic minorities routinely underuse palliative and hospice care, even when there is access to this type of care [23]. Peer mentoring as a culturally sensitive approach to inform AAs on ACP may be particularly effective [26]. Other factors contributing to the underutilization of hospice care among AAs include fears of unfair treatment, withholding potentially life-saving measures, and the predominance of CAs among healthcare practitioners $[27,28]$.

Studies have reported barriers to AAs using hospice services, including philosophical differences; cultural mistrust; the influence of culture, family, and spirituality; and inadequate health insurance [27, 29-34]. Reese et al. [28] describe a fundamental difference between AAs and the European culture of care of the terminally ill, as the AA culture emphasizes living and prolonging life, whereas the traditional European approach favors helping people plan for and cope with eventual death. Hospice programs stress the acceptance of death during the terminal phases of life and palliative care, whereas AAs value aggressive life-sustaining treatments $[28,33,35]$. In a survey of 200 respondents, Blackhall et al. [29] found that AAs were more likely to request life support in the face of terminal illness. In fact, AAs are more hesitant to: agree to withdraw life-prolonging therapies; consent to tissue and organ donations; and participate in palliative care programs [29]. Haber describes AAs as having an expectation of long life and embracing a religious belief of "not giving up" [36]. Cykert et al. [37] found that AAs had a significantly higher health utility score, meaning a greater preference to remain alive despite severe disability. As a corollary to their reluctance to withhold or withdraw aggressive treatment during terminal illness, AAs are least likely to discuss advance directives [31]. Caralis et al. [38] found that AAs believed that they might be treated differently or cared for less well if they had a living will.

The underutilization of palliative care and hospice services must be better understood and initiatives undertaken if the American healthcare system is expected to meet the goals of eliminating race-based health disparities, increasing accessibility to healthcare services, and providing culturally competent care. In contrast to previous reports that AAs were less likely to utilize hospice services [39], a recent study by Colon and Lyke [40] compared hospice utilization by 2,430 AAs (12.55\% population studied) to their prevalence in the general population $(7.06 \%)$ and showed encouraging results. The study showed that between 2004 and 2010, AAs in southern New Jersey were more likely than European Americans, Latinos or Asians to utilize hospice services. As the National Hospice and Palliative Care Organization continues its efforts to increase awareness about hospice, it is hoped that the disparities in EOL support and palliative care for AAs with ESRD will diminish.

\section{Practitioner-Related Factors}

Practitioner-related issues that contribute to disparities in ESRD care for AAs include inadequate communications, treatment misconceptions, and lack of appropriate and timely care [41]. AAs also experience health disparities associated with poor access to timely health education from practitioners, health educators, knowledge of advanced CKD/ESRD awareness programs, and reduced access to clinical research [42].

AAs have higher rates of ESRD compared to individuals of European Americans with a lifetime risk of ESRD for AAs residing in the United States of 7.5\% compared to $2.1 \%$ among European Americans [40]. While many factors have been associated with the higher risk of kidney disease in AAs, no clear genetic link between kidney disease and AAs was established until studies linked non-diabetic kidney disease with 2 distinct alleles within a $60 \mathrm{~kb}$ region of chromosome 22 [10]. Earlier studies in 2008 suggested a genetic factor associated with renal disease, connecting variants of the MYH9 gene to an increased risk of CKD and ESRD in AAs [43]. Subsequent studies clarified this association to variants of the Apolipoprotein-1 gene (APOL-1) that explained a large fraction of risk factors in AAs $[44,45]$. Increasing knowledge of the influence of this genetic risk may lead to advanced research and pharmacogenomics testing toward achieving personalized care for AAs with ESRD.

\section{APOL1 Variants and Pharmacogenomics for Precision} Medicine for AAs with ESRD

Apolipoprotein-1 is expressed in the lung, placenta, pancreas, liver, and kidney [46]. However, long before APOL1 had a known role in kidney disease, it was known as the trypanolytic factor of human serum, protecting humans and other primates against African try-
158

Am J Nephrol 2017;46:156-164 DOI: $10.1159 / 000479479$
Harding/Mersha/Webb/Vassalotti/ Nicholas 
panosomes [47], which cause the deadliest form of African sleeping sickness [44]. Improved survival of individuals with the risk alleles in the trypanosome belt may at least partly explain the high frequency of these deleterious variants in people of African ancestry [10]. Genetic variants in the APOL1 gene confer innate immunity against African trypanosomes, but individuals expressing 2 copies of the APOL- 1 risk alleles (denoted as G1 and G2) have an increased risk of kidney disease relative to those with zero or one copy of APOL-1 gene variants. It is estimated that $\sim 13 \%$ of AAs residing in the United States express 2 copies of the APOL-1 risk alleles [48] and that their lifetime risk of CKD is approximately $15 \%$ [49].

The association between APOL-1 variants and progression to ESRD has been reported to vary based upon the CKD etiology with strong associations between APOL-1 variants and focal and segmental glomerulosclerosis, human immunodeficiency virus, hypertensive, and sickle cell nephropathy [50]. This new knowledge of the impact of APOL1-risk variants on kidney disease in AAs provides the foundation to explore and discover novel therapies to precisely target AAs and subsequently impact the disparities in ESRD and its clinical outcomes. Thus, increasing attention is being given to the implications of self-reported race and ethnicity and ancestry in describing genomic variation-based precision medicine [51].

The National Institute of Health (NIH) National Institute on Minority Health and Health Disparities launched a new health disparities research program exploring the potential for precision medicine to promote health equity and advance the science of minority health and health disparities for all populations [52]. Precision medicine is the study of how a person's genetic makeup influences his or her response to drugs and is one of the cornerstones of personalized medicine in which drugs and drug combinations may be tailored to a patient's genetic profile [53, 54]. Precision medicine can also provide tools for personalized medication regimens and information about potential drug interactions.

Pharmacogenomic testing has been increasingly used to optimize drug regimens that have the potential to promote research in precision medicine for CKD and ESRD [55]. In addition, National Institute on Minority Health and Health Disparities is developing guidelines for pharmacogenomic and precision medicine tools to (a) identify critical biomarkers for disease progression and drug responses in diverse populations and (b) translate pharmacogenomic discoveries into clinical practice, including

Optimizing Care of AAs with ESRD effective treatments [56]. The randomized controlled study on Genetic testing to Understand and Address Renal Disease Disparities will provide meaningful information on the possible incorporation of genetic testing in clinical practice on renal surveillance that will target AAs with hypertension. Thus, genomic discovery for kidney disease in AAs provides a platform for the potential success of these tools to address genetic-based health disparities in AA patients with ESRD.

\section{Interventions to Address the Disparities in ESRD Care of AAs}

Interventions that the practitioner can support include increasing timely nephrology referral, equal access to care, and education about ESRD therapies (particularly home dialysis). The use of informatics at the point of care, and improved continuity of care may also address disparities in the care of AAs with ESRD [57]. A retrospective cohort study of the clinical database of the department of defense medical system of beneficiaries with CKD stages 3-5 indicated that over the period of 12 months, compliance with the National Kidney Disease Outcomes Quality Initiatives clinical and biochemical targets was essentially identical for both AAs and CAs, or in a number of cases, higher for AAs than for CAs [58]. The equity in achieved clinical and biochemical targets was attributed to the positive influence of equal access to care, early referral, and compliance with Kidney Disease Outcomes Quality Initiatives targets related to identification of disease progression and treatment [58].

Peritoneal dialysis and in-home hemodialysis are patient-centric treatment modalities that should be offered to all ESRD individuals. Data from 2014 show that AAs compared to CAs are underrepresented in the in-home dialysis population (6.4 vs. 9.2\%) [1]. This racial disparity may be inaccurately ascribed to the entire nation, since considerable regional and inter-state variability exist. The intervention thought to most likely attenuate the racial disparities of in-home dialysis and access to kidney transplantation is improved education [59], and particularly education of potential donors, recipients and clinicians $[60,61]$. The first step in the process would be early diagnosis and referral to a nephrologist for the patient with advanced CKD to allow more time for education. Notably, Medicare covers up to 6 sessions of education services for advanced CKD (stage IV) patients to learn about kidney disease [62]. This would al-

Am J Nephrol 2017;46:156-164 159 
low for more timely preparation that would facilitate the possibility of preemptive kidney transplant and home dialysis therapies. Sequence and time of educational interventions are important to emphasize for a population that has multiple challenges as outlined in this paper. Simple education delivery to patients may be the most scalable for dissemination, and should include education for dialysis clinic staff as well as nephrologists. Effective strategies for providing education may include patient navigators [8], and dedicated patient educators who visit dialysis clinics and/or visit patients in their social environment [63], and the use of live donor champions [64].

Although hemodialysis patients have an overall higher mortality rate relative to the general population, for many years a paradoxical $45 \%$ lower mortality in AAs vs. CAs has been observed in the hemodialysis setting [65]. The reasons for this are not entirely clear but likely include younger age ( $<50$ years) at dialysis initiation and higher body mass index despite other factors such as higher use of catheters that would increase mortality [66]. This reverse disparity results in bias among clinicians to not refer AA hemodialysis patients for transplantation, since some have suggested that dialysis should be the preferred therapy for ESRD in Black patients [67]. However, US Renal Data System data indicate that the advantages of transplantation over dialysis, including significant prolongation of life expectancy, are enjoyed by AAs as well as all other races or ethnic backgrounds [4].

\section{ESRD Informatics at the Point of Care}

There is an opportunity to develop a new paradigm that identifies and defines the clinical, environment, and socioeconomic dataset that provides the most accurate indicator of health status and well-being of AAs ESRD. There is also an essential need for a core set of meta-data attributes that key clinical, financial, and administrative stakeholders can benefit from to ensure care coordination and continuity of care for the ESRD patient. In a study of CKD of unknown origin, which causes ESRD in tropical countries, Wimalawansa and Wimalawansa [68] created a multifactorial etiology model of 3 meta-data domains that could reduce the overall health outcome due to genetic or other disposition. The premise of the model was to determine the impact of hard or soft water on patients, along with clinical and sociological factors. The author showed, through longitudinal studies, that in contrast to previous dogma, there is no measurable impact of these factors on the outcome of patients with CKD [42]. In a similar way, common risk factors for progressive CKD in the United States may be incorporated into a model specific for ESRD. This would spur the development of more comprehensive clinical assessments, and expand the use of industry codes and modifiers to provide new insights into the impact of environmental toxins, such as exposure to lead, on clinical outcomes.

\section{Development of a Continuity of Care Data Model for ESRD}

A continuity of care data model specifically for ESRD may be developed based on a study conducted by Huang et al. [69]. A comprehensive approach was developed across the kidney disease spectrum including death. A visualization tool was created based on a Sankey diagram that represented the comorbidity and progression of kidney disease over time. The tool has the potential to help clinicians when deciding on the management of ESRD patients [69]. In terms of medical education, it can be used to assist with understanding the nature of a complex chronic disease by showing the dynamics between the comorbidities and ESRD outcomes in a temporal fashion. The author hypothesized that data visualization of comorbidities and outcomes may lead to better understanding of the disease pathogenesis [69]. Efforts in this direction will eventually aid in prediction and disease prevention, personalization of diagnosis and treatment, as well as greater participation of patients in the healthcare system.

\section{National Kidney Disease Education Program Health} Information Technology Workgroup

The NIH National Institute of Diabetes and Digestive and Kidney Diseases National Kidney Disease Education Program Health Information Technology Workgroup and 3 subgroups (the CKD Care Plan Working Group, the CKD Computable Phenotype Working Group, and the CKD Business Case Working Group) recently launched the Managing Chronic Disease Populations through Health Information Technology platform [70]. The workgroup consists of a multidisciplinary team of clinicians, patient advocates, and public health and health information technology specialists to guide the development of a comprehensive clinical data set that is specifically designed to enable ESRD care teams to capture essential information aligned to best practices in care management at all stages of CKD, including ESRD. In addition, the mission of the workgroup is to ensure that data specifications can be adapted to electronic health record standards supported by the Department of Health and Human Services. Incorporating a structured data set into elec-
160

Am J Nephrol 2017;46:156-164 DOI: $10.1159 / 000479479$
Harding/Mersha/Webb/Vassalotti/ Nicholas 
Table 1. Summary of disparities in care of AAs with ESRD

\begin{tabular}{|c|c|c|c|}
\hline Disparity & Concerns & References & Interventions and call to action \\
\hline \multirow[t]{3}{*}{$\begin{array}{l}\text { Patient-, } \\
\text { community-related }\end{array}$} & $\begin{array}{l}\text { Psychosocial, demographic, environmental, } \\
\text { cultural-behavioral factors }\end{array}$ & {$[13-16,19-21]$} & $\begin{array}{l}\text { Enhance patient engagement, patient } \\
\text { education, use of patient navigators/educators, } \\
\text { live donor champions }\end{array}$ \\
\hline & $\begin{array}{l}\text { Awareness of risks and progression of CKD/ } \\
\text { ESRD, fear of healthcare systems, end-of-life } \\
\text { support, use of hospice care }\end{array}$ & {$[23-26,30]$} & Provide equal access to education \\
\hline & $\begin{array}{l}\text { Equal access to education, socioeconomic } \\
\text { status, awareness of healthcare policies }\end{array}$ & {$[15,16,19-21]$} & \\
\hline \multirow[t]{3}{*}{ Practitioner-related } & $\begin{array}{l}\text { Inadequate communication, treatment } \\
\text { misconceptions, lack of appropriate/timely } \\
\text { care, poor access to health education, } \\
\text { reduced access to research Access to home } \\
\text { dialysis therapies }\end{array}$ & {$[42,43]$} & $\begin{array}{l}\text { Timely referrals for preemptive transplantation, } \\
\text { reduce bias } \\
\text { Enhance education, compliance with KDOQI } \\
\text { guidelines } \\
\text { Provide equal access to home dialysis } \\
\text { Encourage utilization of Medicare-covered } \\
\text { education services }\end{array}$ \\
\hline & $\begin{array}{l}\text { Genetic-risk for progressive kidney disease, } \\
\text { pharmacogenomic testing for precision } \\
\text { medicine }\end{array}$ & $\begin{array}{l}{[44-46} \\
51,54,57]\end{array}$ & $\begin{array}{l}\text { Participate in NIMHD precision medicine } \\
\text { research program to promote health equity }\end{array}$ \\
\hline & $\begin{array}{l}\text { Predominance of CAs among } \\
\text { healthcare practitioners }\end{array}$ & & $\begin{array}{l}\text { Enhance accountable partnerships } \\
\text { Advance use of clinical intelligence } \\
\text { Continuity of care } \\
\text { Develop multifactorial risk-factor data model } \\
\text { to predict health status } \\
\text { Adapt comprehensive clinical dataset to the } \\
\text { EHR } \\
\text { Encourage discussion on advance care planning }\end{array}$ \\
\hline
\end{tabular}

tronic health records will significantly improve the clinical intelligence of providers treating patients who are at risk for ESRD, especially AAs.

\section{Call to Action}

The development of ESRD knowledge management and patient engagement strategies that reflect evidencebased care plans focused on mitigating social determinants is essential. These types of care plans would facilitate best practices in disease management for ESRD. Based on this review, an approach may consist of the following strategies. Please see Table 1 for a summary.

\section{Enhance Patient Engagement}

Develop a culturally sensitive patient-engagement strategy that addresses the need to acknowledge preexisting reservation and distrust that AAs with ESRD have

Optimizing Care of AAs with ESRD experienced related to his or her patient care. This includes proactively initiating provider-patient discussions regarding mutual healthcare goals, EOL choices and social determinant factors that may impede patients' ability to achieve their goals. The current timing cannot be better, given the renewed advocacy and funding of nationally recognized efforts sponsored by the Centers for Medicare and Medicaid Services and the Centers for Disease Control and Prevention to address healthcare disparities in ESRD. These include national initiatives such as Centers for Disease Control and Prevention's Healthy People campaign to address healthcare disparities for high-risk patient populations based on race, gender, and sexual orientation [71].

\section{Enhance Professional and Patient Education}

The National Kidney Foundation and the American Society of Nephrology have both been instrumental in providing guidelines and education related to the care of 
patients at all stages of CKD. Recent strategies to disseminate education to primary care physicians on CKD by the National Kidney Foundation and recommendations to Centers for Medicare and Medicaid Services addressing new pathways to optimize quality of care for patients may succeed in reducing healthcare disparities of high risk AA patients with ESRD. A concerted effort by other new and established organizations committed to the care of patients with ESRD would greatly enhance these efforts.

\section{Enhance Accountable Partnerships}

Accountable Care Organizations are groups of doctors, hospitals, and other health care providers who come together voluntarily to give coordinated, high-quality care to their Medicare patients. Through the Affordable Care Act of 2010, the goals of Accountable Care Organizations were to ultimately improve the clinical outcomes of patients with CKD and ESRD. To further advance the goals of these partnerships, primary care physicians and multi-specialty practices who treat ESRD should consider the current knowledge, data management maturity, and the strategic approaches necessary to improve areas of healthcare and health disparities faced by AAs. The recommendation goes beyond incentivized efforts supported by private and federal payer initiatives. Another approach to reduce or eliminate disparities in the care of AAs with ESRD may include a complete assessment of the points of failure at all levels and implementation of accountable partnerships between the patient, the provider and the payer. The advent of sophisticated information technology provides a population health platform for accurate data collection that may facilitate coordinated care, identification and implementation of new, related policy measures, and ultimately significantly improved clinical outcomes for AAs with ESRD.

\section{Advance the Use of Clinical Intelligence:}

There should be a long-term approach to the process of evolving the practice to achieve measurable goals associated with clinical intelligence and population health management as well as clinical risk intervention and predictive analytics. The impact of nontraditional factors and clinical intelligence that are not sufficiently covered within ESRD medical training that may directly impact outcomes in the care for AAs should be investigated. This includes areas related to environmental factors in addition to sociological, behavioral, and clinical determinants that AAs with ESRD may face as barriers to consistent healthcare delivery. The goal would be to develop a care model (being developed by co-authors) that supports and leverages personalized medicine and available digital platforms, with access to industry and quality-certified CKD and ESRD databases and knowledge networks.

\section{Conclusion}

A new era of opportunity to reverse the trend of healthcare disparities within the AA ESRD patient population is within the reach of the healthcare community. It is essential to convert the significant concerns of healthcare disparities into prioritized efforts in order to achieve improved outcomes for this high-risk patient population. By the year 2050, racial and ethnic minority groups will comprise most of the US population. Thus, there is an urgent need for research studies focused on the elimination or reduction of health disparities including ESRD in AAs to reduce or eliminate potentially significant burdens on the healthcare system, and the society at large.

\section{Acknowledgment}

This work was supported by NIH grant R01HL132344 to TBM; and NIH grants 1DP3 DK094311 and UL1TR000124 to SBN. The authors would also like to thank Benjamin Bobbitt for his contribution.

\section{Disclosure Statement}

The authors claim no conflicts of interest. The content is solely the responsibility of the authors and the authors declare that they have no relevant financial interests.

References

Saran R, Li Y, Robinson B, Ayanian J, Balkrishnan R, Bragg-Gresham J, Chen JT, Cope E, Gipson D, He K, Herman W, Heung M, Hirth RA, Jacobsen SS, Kalantar-Zadeh K, Kovesdy CP, Leichtman AB, Lu Y, Molnar MZ, Morgenstern $\mathrm{H}$, Nallamothu B, O'Hare AM, Pisoni $\mathrm{R}$, Plattner B, Port FK, Rao P, Rhee CM, Schaubel DE, Selewski DT, Shahinian V, Sim JJ, Song P, Streja E, Kurella Tamura M, Tentori F, Eggers PW, Agodoa LY, Abbott KC: US renal data system 2014 annual data report: epidemiology of kidney disease in the United States. Am J Kidney Dis 2015;66(1 suppl 1):Svii, S1-S305.

2 https://www.niddk.nih.gov/health-information/health-statistics/Pages/kidneydisease-statistics-united-states.aspx\#top (accessed January 27, 2017).

3 Kidney Disease Statistics for the United States: National Kidney and Urologic Diseases Information Clearinghouse, NIH Publication No. 12-3895, 2012, pp 1-16.

Harding/Mersha/Webb/Vassalotti/

Nicholas
Am J Nephrol 2017;46:156-164 DOI: $10.1159 / 000479479$

162 
4 https://www.cdc.gov/nchs/data/nvsr/nvsr64/ nvsr64_02.pdf (accessed January 27, 2017).

5 Choi AI, Rodriguez RA, Bacchetti P, Bertenthal D, Hernandez GT, O'Hare AM: White/ black racial differences in risk of end-stage renal disease and death. Am J Med 2009;122: 672-678.

-6 Coresh J, Astor BC, Greene T, Eknoyan G, Levey AS: Prevalence of chronic kidney disease and decreased kidney function in the adult us population: third national health and nutrition examination survey. Am J Kidney Dis 2003;41:1-12.

7 Collins AJ, Foley RN, Chavers B, Gilbertson D, Herzog C, Johansen K, Kasiske B, Kutner N, Liu J, St Peter W, Guo H, Gustafson S, Heubner B, Lamb K, Li S, Li S, Peng Y, Qiu Y, Roberts T, Skeans M, Snyder J, Solid C, Thompson B, Wang C, Weinhandl E, Zaun D, Arko C, Chen SC, Daniels F, Ebben J, Frazier E, Hanzlik C, Johnson R, Sheets D, Wang X, Forrest B, Constantini E, Everson S, Eggers P, Agodoa L: United States renal data system 2011 annual data report: atlas of chronic kidney disease \& end-stage renal disease in the United States. Am J Kidney Dis 2012;59(1 suppl 1):A7.e1-e420.

$\checkmark 8$ Collins AJ, Foley RN, Herzog C, Chavers B, Gilbertson D, Ishani A, Kasiske B, Liu J, Mau LW, McBean M, Murray A, St Peter W, Guo H, Gustafson S, Li Q, Li S, Li S, Peng Y, Qiu Y, Roberts T, Skeans M, Snyder J, Solid C, Wang C, Weinhandl E, Zaun D, Arko C, Chen SC, Dalleska F, Daniels F, Dunning S, Ebben J, Frazier E, Hanzlik C, Johnson R, Sheets D, Wang X, Forrest B, Constantini E, Everson S, Eggers P, Agodoa L: US renal data system 2010 annual data report. Am J Kidney Dis 2011;57(1 suppl 1):A8.e1-e526.

9 Jayasinghe S: Chronic kidney disease of unknown etiology should be renamed chronic agrochemical nephropathy. MEDICC Rev 2014;16:72-74.

10 Friedman DJ, Pollak MR: Genetics of kidney failure and the evolving story of APOL1. Clin Invest 2011;121:3367-3374.

11 Pollak MR: Familial FSGS. Adv Chronic Kidney Dis 2014;21:422-425.

12 Guan M, Ma J, Keaton JM, Dimitrov L, Mudgal P, Stromberg M, Bonomo JA, Hicks PJ, Freedman BI, Bowden DW, Ng MC: Association of kidney structure-related gene variants with type 2 diabetes-attributed end-stage kidney disease in African Americans. Hum Genet 2016;135:1251-1262.

13 Powe NR, Melamed ML: Racial disparities in the optimal delivery of chronic kidney disease care. Med Clin North Am 2005;89:475-488.

14 Ward MM: Socioeconomic status and the incidence of ESRD. Am J Kidney Dis 2008;51: 563-572.

15 Evans RW, Blagg CR, Bryan FA Jr: Implications for health care policy. A social and demographic profile of hemodialysis patients in the United States. JAMA 1981;245:487-491.

16 Alves TP, Wang X, Wright JT Jr, Appel LJ, Greene T, Norris K, Lewis J; AASK Collab- orative Research Group: Rate of ESRD exceeds mortality among African Americans with hypertensive nephrosclerosis. J Am Soc Nephrol 2010;21:1361-1369.

17 Klag MJ, Whelton PK, Randall BL, Neaton JD, Brancati FL, Stamler J: End-stage renal disease in African-American and white men. 16-year MRFIT findings. JAMA 1997;277:1293-1298.

18 Crews DC, Charles RF, Evans MK, Zonderman AB, Powe NR: Poverty, race, and CKD in a racially and socioeconomically diverse urban population. Am J Kidney Dis 2010;55: 992-1000.

19 Lipworth L, Mumma MT, Cavanaugh KL, Edwards TL, Ikizler TA, Tarone RE, McLaughlin $\mathrm{JK}$, Blot WJ: Incidence and predictors of end stage renal disease among low-income blacks and whites. PLoS One 2012;7:e48407.

20 Nicholas SB, Kalantar-Zadeh K, Norris KC: Socioeconomic disparities in chronic kidney disease. Adv Chronic Kidney Dis 2015;22:6-15.

21 Feder J, Nadel MV, Krishnan M: A matter of choice: opportunities and obstacles facing people with ESRD. Clin J Am Soc Nephrol 2016;11:536-538.

22 Kazley AS, Johnson E, Simpson K, Chavin K, Baliga P: African American patient knowledge of kidney disease: a qualitative study of those with advanced chronic kidney disease. Chronic Illn 2015;11:245-255.

23 Cukor D, Kimmel PL: Education and end of life in chronic kidney disease: disparities in black and white. Clin J Am Soc Nephrol 2010; 5:163-166.

- 24 Salter ML, Kumar K, Law AH, Gupta N, Marks K, Balhara K, McAdams-DeMarco MA, Taylor LA, Segev DL: Perceptions about hemodialysis and transplantation among African American adults with end-stage renal disease: inferences from focus groups. BMC Nephrol 2015;16:49.

25 Norris KC, Nicholas SB: Racial disparities in end-of-life issues in patients with chronic kidney disease. Am J Nephrol 2016;44:81-83.

26 Perry E, Swartz J, Brown S, Smith D, Kelly G, Swartz R: Peer mentoring: a culturally sensitive approach to end-of-life planning for long-term dialysis patients. Am J Kidney Dis 2005;46:111-119.

27 Cort MA: Cultural mistrust and use of hospice care: challenges and remedies. J Palliat Med 2004;7:63-71.

28 Reese DJ, Ahern RE, Nair S, O’Faire JD, Warren C: Hospice access and use by African Americans: addressing cultural and institutional barriers through participatory action research. Soc Work 1999;44:549-559.

29 Blackhall LJ, Frank G, Murphy ST, Michel V, Palmer JM, Azen SP: Ethnicity and attitudes towards life sustaining technology. Soc Sci Med 1999;48:1779-1789.

30 Burrs FA: The African American experience: breaking the barriers to hospices. Hosp J 1995; 10:15-18.

31 Dupree CY: The attitudes of black Americans toward advance directives. J Transcult Nurs 2000;11:12-18.
32 Gordon AK: Deterrents to access and service for blacks and hispanics: the medicare hospice benefit, healthcare utilization, and cultural barriers. Hosp J 1995;10: 65-83.

33 Krakauer EL, Crenner C, Fox K: Barriers to optimum end-of-life care for minority patients. J Am Geriatr Soc 2002;50:182-190.

34 OMara AM, Arenella C: Minority representation, prevalence of symptoms, and utilization of services in a large metropolitan hospice. J Pain Symptom Manage 2001;21:290297.

35 Garrett JM, Harris RP, Norburn JK, Patrick DL, Danis M: Life-sustaining treatments during terminal illness: who wants what? J Gen Intern Med 1993;8:361-368.

36 Schena FP: Biomarkers and personalized therapy in chronic kidney diseases. Expert Opin Investig Drugs 2014;23:1051-1054.

37 Cykert S, Jones JD, Kissling G, Hansen CJ: Racial differences in patients' perceptions of debilitated health states. J Gen Intern Med 1999; 14:217-222.

38 Caralis PV, Davis B, Wright K, Marcial E: The influence of ethnicity and race on attitudes toward advance directives, life-prolonging treatments, and euthanasia. J Clin Ethics 1993;4:155-165.

-39 Arenella C: Hospice and palliative care for African Americans: overcoming disparities. J Palliat Med 2016;19:126.

40 Colon M, Lyke J: Comparison of hospice use by European Americans, African Americans, and latinos: a follow-up study. Am J Hosp Palliat Care 2015;32:205-209.

-41 Boulware LE, Troll MU, Jaar BG, Myers DI, Powe NR: Identification and referral of patients with progressive CKD: a national study. Am J Kidney Dis 2006;48:192-204.

42 Nicholas SB, Tareen N, Zadshir A, Martins D, Pan D, Norris KC: Management of early chronic kidney disease in indigenous populations and ethnic minorities. Kidney Int Suppl 2005;97:S78-S81.

43 Kao WH, Klag MJ, Meoni LA, Reich D, Berthier-Schaad Y, Li M, Coresh J, Patterson N, Tandon A, Powe NR, Fink NE, Sadler JH, Weir MR, Abboud HE, Adler SG, Divers J, Iyengar SK, Freedman BI, Kimmel PL, Knowler WC, Kohn OF, Kramp K, Leehey DJ, Nicholas SB, Pahl MV, Schelling JR, Sedor JR, Thornley-Brown D, Winkler CA, Smith MW, Parekh RS; Family Investigation of Nephropathy and Diabetes Research Group: MYH9 is associated with nondiabetic end-stage renal disease in African Americans. Nat Genet 2008; $40: 1185-1192$.

44 Genovese G, Friedman DJ, Ross MD, Lecordier L, Uzureau P, Freedman BI, Bowden DW, Langefeld CD, Oleksyk TK, Uscinski Knob AL, Bernhardy AJ, Hicks PJ, Nelson GW, Vanhollebeke B, Winkler CA, Kopp JB, Pays E, Pollak MR: Association of trypanolytic Apol1 variants with kidney disease in African Americans. Science 2010;329:841845. 
-45 Tzur S, Rosset S, Shemer R, Yudkovsky G, Selig S, Tarekegn A, Bekele E, Bradman N, Wasser WG, Behar DM, Skorecki K: Missense mutations in the APOL1 gene are highly associated with end stage kidney disease risk previously attributed to the MYH9 gene. Hum Genet 2010;128:345-350.

46 Uhlen M, Fagerberg L, Hallstrom BM, Lindskog C, Oksvold P, Mardinoglu A, Sivertsson A, Kampf C, Sjostedt E, Asplund A, Olsson I, Edlund K, Lundberg E, Navani S, Szigyarto CA, Odeberg J, Djureinovic D, Takanen JO, Hober S, Alm T, Edqvist PH, Berling H, Tegel H, Mulder J, Rockberg J, Nilsson P, Schwenk JM, Hamsten M, von Feilitzen K, Forsberg M, Persson L, Johansson F, Zwahlen M, von Heijne G, Nielsen J, Ponten F: Proteomics. Tissue-based map of the human proteome. Science 2015;347:1260419.

47 Vanhamme L, Paturiaux-Hanocq F, Poelvoorde P, Nolan DP, Lins L, Van Den Abbeele J, Pays A, Tebabi P, Van Xong H, Jacquet A, Moguilevsky N, Dieu M, Kane JP, De Baetselier P, Brasseur R, Pays E: Apolipoprotein L-I is the trypanosome lytic factor of human serum. Nature 2003;422:83-87.

48 Tishkoff SA, Reed FA, Friedlaender FR, Ehret C, Ranciaro A, Froment A, Hirbo JB, Awomoyi AA, Bodo JM, Doumbo O, Ibrahim M, Juma AT, Kotze MJ, Lema G, Moore JH, Mortensen H, Nyambo TB, Omar SA, Powell K, Pretorius GS, Smith MW, Thera MA, Wambebe C, Weber JL, Williams SM: The genetic structure and history of Africans and African Americans. Science 2009;324:1035-1044.

49 Dummer PD, Limou S, Rosenberg AZ, Heymann J, Nelson G, Winkler CA, Kopp JB: APOL1 kidney disease risk variants: an evolving landscape. Semin Nephrol 2015;35:222236.

50 Papeta N, Kiryluk K, Patel A, Sterken R, Kacak N, Snyder HJ, Imus PH, Mhatre AN, Lawani AK, Julian BA, Wyatt RJ, Novak J, Wyatt CM, Ross MJ, Winston JA, Klotman ME, Cohen DJ, Appel GB, D'Agati VD, Klotman PE, Gharavi AG: APOL1 variants increase risk for FSGS and HIVAN but not IgA nephropathy. J Am Soc Nephrol 2011;22:1991-1996.
51 Mersha TB, Abebe T: Self-reported race/ethnicity in the age of genomic research: Its potential impact on understanding health disparities. Hum Genomics 2015;9:1.

52 https://www.nih.gov/news-events/newsreleases/nih-funds-precision-medicineresearch-focus-health-disparities (accessed January 30, 2017).

53 https://www.fda.gov/scienceresearch/specialtopics/precisionmedicine/default.htm (accessed April 2017).

54 Mizzi C, Peters B, Mitropoulou C, Mitropoulos K, Katsila T, Agarwal MR, van Schaik RH, Drmanac R, Borg J, Patrinos GP: Personalized pharmacogenomics profiling using whole-genome sequencing. Pharmacogenomics 2014; 15:1223-1234.

55 Phelps KR, Mason DL, Stote KS: Phosphate homeostasis, parathyroid hormone, and fibroblast growth factor 23 in stages 3 and 4 chronic kidney disease. Clin Nephrol 2016; 85:251-261.

56 https://www.nih.gov/news-events/newsreleases/nih-funds-precision-medicineresearch-focus-health-disparities (accessed April 2017).

57 Williams AW: Health policy, disparities, and the kidney. Adv Chronic Kidney Dis 2015;22: 54-59.

58 Gao SW, Oliver DK, Das N, Hurst FP, Lentine KL, Agodoa LY, Sawyers ES, Abbott KC: Assessment of racial disparities in chronic kidney disease stage 3 and 4 care in the department of defense health system. Clin J Am Soc Nephrol 2008;3:442-449.

59 Lockridge RS, Kjellstrand CM: Nightly home hemodialysis: outcome and factors associated with survival. Hemodial Int 2011;15:211-218.

60 Wallace EL, Lea J, Chaudhary NS, Griffin R, Hammelman E, Cohen J, Sloand JA: Home dialysis utilization among racial and ethnic minorities in the United States at the national, regional, and state level. Perit Dial Int 2017; 37:21-29.

61 Patzer RE, Gander J, Sauls L, Amamoo MA, Krisher J, Mulloy LL, Gibney E, Browne T, Plantinga L, Pastan SO; Southeastern Kidney Transplant Coalition: The radiant communi- ty study protocol: community-based participatory research for reducing disparities in access to kidney transplantation. BMC Nephrol 2014; $15: 171$.

62 https://www.medicare.gov/coverage/kidneydisease-edu.html (accessed April 2017)

63 Waterman AD, Peipert JD, Goalby CJ, Dinkel KM, Xiao H, Lentine KL: Assessing transplant education practices in dialysis centers: comparing educator reported and medicare data. Clin J Am Soc Nephrol 2015;10:1617-1625.

64 Garonzik-Wang JM, Berger JC, Ros RL, Kucirka LM, Deshpande NA, Boyarsky BJ, Montgomery RA, Hall EC, James NT, Segev DL: Live donor champion: finding live kidney donors by separating the advocate from the patient. Transplantation 2012;93:1147-1150.

65 Agodoa L, Eggers P: Racial and ethnic disparities in end-stage kidney failure-survival paradoxes in African-Americans. Semin Dial 2007;20:577-585.

66 Kucirka LM, Grams ME, Lessler J, Hall EC, James N, Massie AB, Montgomery RA, Segev DL: Association of race and age with survival among patients undergoing dialysis. JAMA 2011;306:620-626

67 Reddan DN, Szczech LA, Klassen PS, Owen WF Jr: Racial inequity in America's ESRD program. Semin Dial 2000;13:399-403.

68 Wimalawansa SA, Wimalawansa SJ: Environmentally induced, occupational diseases with emphasis on chronic kidney disease of multifactorial origin affecting tropical countries. Ann Occup Environ Med 2016;28:33.

69 Huang CW, Syed-Abdul S, Jian WS, Iqbal U, Nguyen PA, Lee P, Lin SH, Hsu WD, Wu MS, Wang CF, Ma KL, Li YC: A novel tool for visualizing chronic kidney disease associated polymorbidity: a 13-year cohort study in Taiwan. J Am Med Inform Assoc 2015;22: 290-298.

70 https://www.niddk.nih.gov/health-information/health-communicationprograms/nkdep/working-groups/health-informationtechnology-working-group/Pages/default. aspx (accessed April 27, 2017).

$71 \mathrm{https}: / /$ www.healthypeople.gov/ (accessed April 27, 2017). 